\title{
01.4
}

\section{Устойчивость углеродной нанолуковицы в контакте с графитовой подложкой}

\author{
(C) С.Ш. Рехвиашвили, М.М. Бухурова \\ Институт прикладной математики и автоматизации КБНЦ РАН, Нальчик, Россия \\ E-mail: rsergo@mail.ru
}

Поступило в Редакцию 19 марта 2019г.

В окончательной редакции 25 марта 2019г.

Принято к публикации 25 марта 2019г.

\begin{abstract}
Предлагается теоретическая модель устойчивости углеродной нанолуковицы в присутствии массивной каталитической фазы графита, основанная на применении континуального приближения для потенциала межатомного взаимодействия и механики деформируемых систем. Показано, что углеродная нанолуковица является неустойчивой, если ее радиус превышает удвоенное значение радиуса молекулы фуллерена $\mathrm{C}_{60}$.
\end{abstract}

Ключевые слова: углеродные наноматериалы, нанолуковица, потенциал взаимодействия, континуальное приближение, механика деформируемых систем.

DOI: 10.21883/PJTF.2019.12.47909.17794

Углеродные наноматериалы активно исследуются и применяются в различных областях, включая медицину, приборостроение, электронику и энергетику. В отличие от таких популярных объектов исследования, как фуллерены, нанотрубки и графен, менее изученными до сих пор остаются углеродные нанолуковицы (carbon onions) и наноалмазы. Нанолуковицы представляют собой сферические частицы, состоящие из вложенных друг в друга углеродных монослойных оболочек. Под воздействием электронного пучка эти частицы могут приобретать достаточно большой радиус - свыше $100 \mathrm{~nm}$ [1-6]. Без электронного воздействия нанолуковицы становятся неустойчивыми и со временем деформируются и разрушаются. Время разрушения находится в широком диапазоне от нескольких минут после прекращения облучения до нескольких месяцев. Общепринятого объяснения механизмов формирования и разрушения углеродных нанолуковиц пока не существует. По нашему мнению, определенную роль должно играть уменьшение поляризуемости всей системы под действием электронного пучка, которое приводит к ослаблению сил Ван-дер-Ваальса, ответственных за деформацию и деструкцию нанолуковиц.

В [7-13] рассматривались различные вопросы устойчивости углеродных нанолуковиц. Здесь следует указать, что какого-либо обоснованного критерия устойчивости этих структур получено не было. Не учитывалось также и влияние окружающей массивной фазы, в присутствии которой, как правило, находятся нанолуковицы. Из простых физических соображений понятно, что наличие массивной фазы будет способствовать потере устойчивости сферической формы и дальнейшей деструкции частиц за счет межатомного взаимодействия. В целом теоретические работы в данном направлении затруднены из-за неопределенности, связанной с незнанием точной атомной структуры нанолуковиц [1]. Ab initio расчеты стабильности больших многослойных частиц методами молекулярной динамики и/или Монте-Карло также пока не доступны.

Настоящая работа посвящена анализу устойчивости углеродной нанолуковицы, находящейся в контакте с полубесконечной графитовой подложкой. В качестве инструмента используются теория механической устойчивости сферических оболочек [14] и континуальное приближение для потенциала межатомного взаимодействия, которое применялось авторами ранее для расчета системы фуллерен-нанотрубка [15].

В континуальном приближении потенциал взаимодействия нанолуковицы с графитовой подложкой дается выражением

$$
U=n^{2} \int_{\Omega_{2}} \int_{\Omega_{1}} \phi(r) d V_{1} d V_{2}
$$

где $r$ - межатомное расстояние, $\phi(r)$ - парный потенциал, $n=1.12 \cdot 10^{29} \mathrm{~m}^{-3}$ - объемная плотность атомов графита. Интегрирование в (1) проводится по объемам взаимодействующих тел. Предполагается, что плотности атомов нанолуковицы и графита имеют одно и то же значение. С использованием сферической системы координат (1) преобразуется к виду

$$
U(z)=(2 \pi n)^{2} \int_{-1}^{1} \int_{0}^{R} \int_{h(\xi, \eta, z)}^{+\infty}[\rho-h(\xi, \eta, z)] \phi(\rho) \rho d \rho \xi^{2} d \xi d \eta
$$

где

$$
h(\xi, \eta, z)=\sqrt{z^{2}+\xi^{2}-2 z \xi \eta},
$$

$z$ - расстояние от центра нанолуковицы до поверхности подложки, $R$ - радиус нанолуковицы. Для парного 


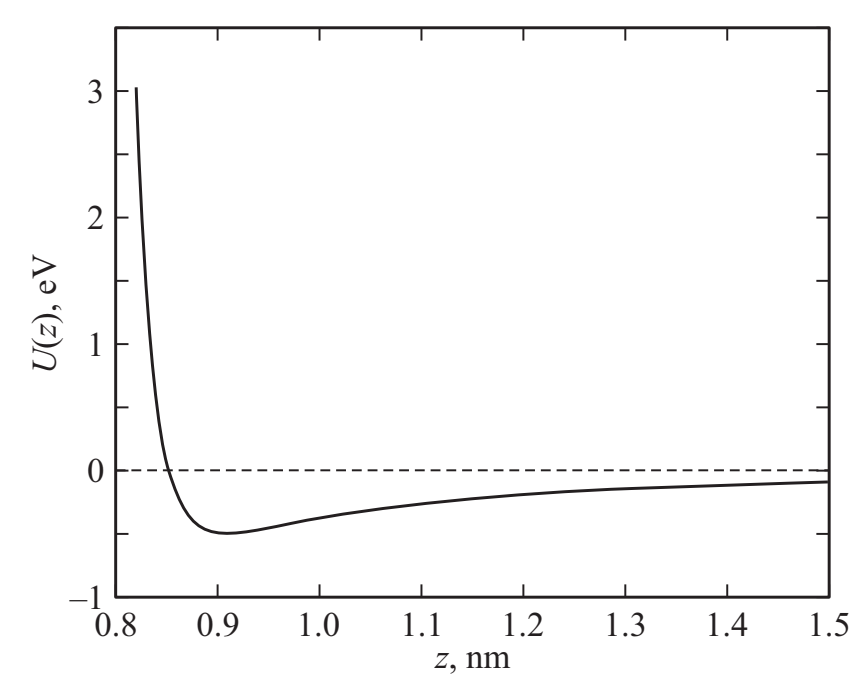

Зависимость потенциала взаимодействия углеродной нанолуковицы с графитовой подложкой от расстояния между ними при $R=2 R_{F}$.

потенциала воспользуемся формулой Леннарда-Джонса

$$
\phi(r)=D\left[\left(\frac{r_{0}}{r}\right)^{12}-2\left(\frac{r_{0}}{r}\right)^{6}\right],
$$

где $D=3.202 \mathrm{meV}$ и $r_{0}=0.3985 \mathrm{~nm}$ - глубина потенциальной ямы и равновесное расстояние [16]. Подставляя (3) в (2) и выполняя интегрирование, находим

$$
\begin{aligned}
U(z) & =\frac{4}{3}(\pi n)^{2} D r_{0}^{6}\left[\frac{r_{0}^{6}}{1575} \frac{3 R^{7}+42 R^{5} z^{2}+35 R^{3} z^{4}}{z\left(z^{2}-R^{2}\right)^{6}}\right. \\
& \left.+\frac{R}{z}-\ln \left(\sqrt{\frac{z+R}{z-R}}\right)\right]
\end{aligned}
$$

где всегда должно выполняться условие $z>R$. При $z \gg R$ из (4) получается асимптотическая формула

$$
U(z)=-\frac{4(\pi n)^{2} D r_{0}^{6} R^{3}}{9 z^{3}}=-\frac{2 A R^{3}}{9 z^{3}}
$$

которая описывает дисперсионное взаимодействие Ван-дер-Ваальса малой сферической частицы с толстой подложкой (A - постоянная Гамакера $[17$, с. 50]). Вычисление сил отталкивания в континуальном приближении возможно по следующим причинам. Во-первых, для сил отталкивания из (2) получается быстросходящийся интеграл. Физически это учитывает тот факт, что силы отталкивания действуют в очень малой области пространства. Во-вторых, в континуальном приближении имеется возможность учесть „мягкость“ сил отталкивания.

Нанолуковица закрепляется на некотором расстоянии $z_{0}$ от поверхности подложки, которое зависит от радиуса $R$ и определяется исходя из условия минимума потенциала (4): $d U(z) / d z=0$. В состоянии равновесия бо́льшая часть нанолуковицы оказывается под действием сил притяжения, а силы отталкивания действуют только на небольшой участок, который расположен в непосредственной близости от подложки. Давление на нанолуковицу определим как силу отталкивания, действующую на элементарную ячейку листа графита (гексагон) со стороны графитовой подложки:

$$
p=\frac{N F}{S}=\frac{4 F}{3 \sqrt{3} a^{2}}
$$

где $F-$ сила отталкивания, действующая на один атом, $N=2$ - число атомов углерода, приходящееся на один гексагон площадью $S=3 \sqrt{3} a^{2} / 2, a=0.142 \mathrm{~nm}-$ межатомное расстояние. Для расчета силы $F$ возьмем отталкивательную часть потенциала атом-пластина, который приведен, в частности, в [18]. В итоге из (6) получается следующая формула:

$$
p=\frac{4 \sqrt{3}}{45} \frac{\pi n D r_{0}^{12}}{a^{2}\left(z_{0}-R\right)^{10}} .
$$

Далее будем предполагать, что разрушение нанолуковицы начинается с потери механической устойчивости (выпучивания) внешней углеродной оболочки. Критическое давление, при котором происходит необратимое выпучивание полой сферической оболочки радиусом $R$ и толщиной $d$, дается формулой Цолли-Лейбензона (Zoelly, 1915 г.; Лейбензон, 1917 г.) [14, с. 651]:

$$
p=\frac{2 E}{\sqrt{3\left(1-v^{2}\right)}}\left(\frac{d}{R}\right)^{2},
$$

где $E$ - модуль Юнга, v - коэффициент Пуассона. Если давление в области контакта нанолуковицы с подложкой превысит критическое значение, рассчитанное согласно (8), то может происходить смещение граничных атомов из их местоположений и образование разупорядоченных зон или краевых дислокаций. Для отдельной оболочки примем следующие параметры графена [19]: $d=0.334 \mathrm{~nm}, E=1.09 \mathrm{TPa}, v=0.13$. Расчеты по (7) и (8) с точностью до двух знаков после запятой дают одно и то же давление $(p=0.28 \mathrm{TPa})$ при следующих значениях равновесного расстояния и радиуса: $z_{0}=0.909 \mathrm{~nm}$ и $R=2 R_{F}$, где $R_{F}=0.357 \mathrm{~nm}$ - радиус молекулы фуллерена $\mathrm{C}_{60}$. Энергия когезии для данного случая $W=-U\left(z_{0}\right)=0.49 \mathrm{eV}$. Зависимость $U(z)$ для указанных значений параметров представлена на рисунке. Равновесное расстояние находилось при заданном радиусе нанолуковицы из решения алгебраического уравнения, которое получается дифференцированием формулы (4). Вычисленное нами значение критического давления для нанолуковицы примерно в 2 раза превышает экспериментальную прочность графена $(0.13 \mathrm{TPa}[20])$ и соответствует прочности одностенных углеродных нанотрубок, если в качестве последней принять величину $0.1 E$, где $E$ - модуль Юнга нанотрубки [21,22]. 
Таким образом, приходим к следующим выводам. Учет взаимодействия нанолуковицы с массивной каталитической фазой приводит к существенному уменьшению ее критического радиуса по сравнению со свободными частицами (см. [11]). С использованием континуального приближения для потенциала взаимодействия и теории механической устойчивости оболочек показано, что радиус устойчивой нанолуковицы, находящейся в контакте с подложкой графита, не может превышать удвоенное значение радиуса молекулы фуллерена $\mathrm{C}_{60}\left(R<2 R_{F}\right)$. Этот вывод согласуется с результатами электронномикроскопических исследований $[1$, с. 279]: стабильные во времени нанолуковицы правильной сферической формы без интенсивного электронного воздействия на поверхностях подложек не обнаруживаются.

\section{Конфликт интересов}

Авторы заявляют, что у них нет конфликта интересов.

\section{Список литературы}

[1] Харрис П. Углеродные нанотрубы и родственные структуры. Новые материалы XXI века. М.: Техносфера, 2003. $336 \mathrm{c}$.

[2] McDonough J.K., Gogotsi Y. // Electrochem. Soc. Interface Fall. 2013. V. 22. N 3. P. 61-66.

[3] Bartelmess J., Giordani S. // Beilstein J. Nanotechnol. 2014. V. 5. N 1. P. 1980-1998.

[4] Zeiger M., Jackel N., Mochalin V.N., Presser V. // J. Mater. Chem. A. 2016. V. 4. P. 3172-3196.

[5] Banhart F. // ФТT. 2002. T. 44. B. 3. C. 388-392.

[6] Кряжев Ю.Г., Коваль Н.Н., Лихолобов В.А., Тересов А.Д., Дроздов В.А., Тренихин М.В. // Письма в ЖТФ. 2012. Т. 38. B. 7. C. $1-6$.

[7] Kitahara H., Okua T., Suganuma K. // Eur. Phys. J. D. 2001. V. 16. P. 361-363.

[8] Erkoc S. // Nano Lett. 2002. V. 2. N 3. P. 215-217.

[9] Barnard A.S., Russo S.P., Snook I.K. // J. Chem. Phys. 2003. V. 118 . N 11. P. 5094-5097.

[10] Anjosa D.M., McDonough J.K., Perrec E., Brown G.M., Overbury S.H., Gogotsi Y., Presser V. // Nano Energy. 2013. V. 2. N 5. P. $702-712$.

[11] Todt M., Bitsche R.D., Hartmann M.A., Fischer F.D., Rammerstorfer F.G. // Int. J. Solids Struct. 2014. V. 51. N 3-4. P. 706-715.

[12] Huang $Q$., Yu D., Xu B., Hu W., Ma Y., Wang Y., Zhao Z., Wen B., He J., Liu Z., Tian Y. // Nature. 2014. V. 510. N 7504. P. 250-253.

[13] Latini A., Tomellini M., Lazzarini L., Bertoni G., Gazzoli D., Bossa L., Gozzi D. // PLoS ONE. 2014. V. 9. N 8. P. e105788.

[14] Вольмир А.С. Устойчивость деформируемых систем. М.: Наука, 1967. 984 с

[15] Рехвиашвили С.Ш., Бухурова М.М. // Письма в ЖТФ. 2018. T. 44. B. 23. C. 24-29.

[16] Palucha S., Gburski Z., Biesiada J. // J. Mol. Struct. 2004. V. 704. N 1. P. 269-273.

[17] Бараш Ю.С. Силы Ван-дер-Ваальса. М.: Наука, 1988. $344 \mathrm{c}$.
[18] Рехвиашвили С.Ш., Бухурова М.М. // ЖФХ. 2018. Т. 92. № 10. C. $1562-1566$.

[19] Минкин А.С., Лебедева И.В., Попов А.М., Книжник А.А. // Письма в ЖТФ. 2019. Т. 45. В. 3. С. 52-54.

[20] Lee C., Wei X., Kysar J.W., Hone J. // Science. 2008. V. 321. N 5887. P. 385-388.

[21] Treacy M.M.J., Ebbesen T.W., Gibson J.M. // Nature. 1996. V. 381. N 6584. P. 678-680.

[22] Lourie O., Wagner H.D. // J. Mater. Res. 1998. V. 13. N 9. P. 2418-2422. 